\title{
The genome-wide binding profile of the Sulfolobus solfataricus transcription factor Ss-LrpB shows binding events beyond direct transcription regulation
}

Trong Nguyen-Duc 1,2,5, Liesbeth van Oeffelen ${ }^{3,4}$, Ningning Song ${ }^{3}$, Gholamreza Hassanzadeh-Ghassabeh ${ }^{1,2}$, Serge Muyldermans ${ }^{1,2}$, Daniel Charlier ${ }^{3}$ and Eveline Peeters ${ }^{3^{*}}$

\begin{abstract}
Background: Gene regulatory processes are largely resulting from binding of transcription factors to specific genomic targets. Leucine-responsive Regulatory Protein (Lrp) is a prevalent transcription factor family in prokaryotes, however, little information is available on biological functions of these proteins in archaea. Here, we study genomewide binding of the Lrp-like transcription factor Ss-LrpB from Sulfolobus solfataricus.

Results: Chromatin immunoprecipitation in combination with DNA microarray analysis (ChIP-chip) has revealed that Ss-LrpB interacts with 36 additional loci besides the four previously identified local targets. Only a subset of the newly identified binding targets, concentrated in a highly variable IS-dense genomic region, is also bound in vitro by pure Ss-LrpB. There is no clear relationship between the in vitro measured DNA-binding specificity of Ss-LrpB and the in vivo association suggesting a limited permissivity of the crenarchaeal chromatin for transcription factor binding. Of 37 identified binding regions, 29 are co-bound by LysM, another Lrp-like transcription factor in S. solfataricus. Comparative gene expression analysis in an Ss-IrpB mutant strain shows no significant Ss-LrpB-mediated regulation for most targeted genes, with exception of the CRISPR B cluster, which is activated by Ss-LrpB through binding to a specific motif in the leader region.

Conclusions: The genome-wide binding profile presented here implies that Ss-LrpB is associated at additional genomic binding sites besides the local gene targets, but acts as a specific transcription regulator in the tested growth conditions. Moreover, we have provided evidence that two Lrp-like transcription factors in S. solfataricus, Ss-LrpB and LysM, interact in vivo.
\end{abstract}

Keywords: Archaea, Sulfolobus, Leucine-responsive regulatory protein, CRISPR, ChIP-chip

\section{Background}

Transcription factors (TFs) belonging to the Leucineresponsive Regulatory Protein (Lrp) family (also known as AsnC or FFRP) are abundant in both bacteria and archaea [1-4]. A sequence analysis of 52 archaeal genomes indicated that they are all predicted to contain at least one lrp-like gene, lrp-like genes constituting in total about $8 \%$ of all non-general TF genes in archaea [4].

\footnotetext{
* Correspondence: espeeter@vub.ac.be

${ }^{3}$ Research group of Microbiology, Vrije Universiteit Brussel, Pleinlaan 2, B-1050 Brussels, Belgium

Full list of author information is available at the end of the article
}

Whereas bacterial Lrp-like TFs regulate amino acid biosynthesis in response to nutritional availability [5], archaeal Lrp members also regulate genes belonging to energy, central metabolism and transport pathways [6-9]. Furthermore, it has been observed and/or predicted by sequence analyses that a subset of archaeal Lrp-like TFs do not interact with amino acids, in contrast to most other archaeal Lrp-like TFs [10-16] and to bacterial Lrp-like regulators that invariably bind amino acids. Known archaeal Lrp-like TFs have regulon sizes ranging from one or a few targets to a large number of genes and operons. Examples of the former are LrpA from Pyrococcus [17], LrpA1 from

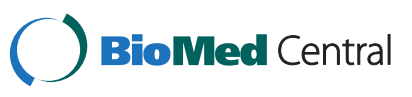


Halobacterium salinarum R1 [15], Ptr2 from Methanocaldococcus jannaschii [6,7] and LysM from Sulfolobus solfataricus that has an intermediate number of target genes [16]. Examples of the latter are FL11 from Pyrococcus OT3 [12], Lrp from H. salinarum R1 [15] and Sa-Lrp from Sulfolobus acidocaldarius [18].

Lrp-like proteins generally have low sequence identities, but are structurally highly conserved [19]. Typically, an Lrp monomer has a molecular mass of about $15 \mathrm{kDa}$ and consists of two domains: an amino-terminal DNA-binding domain with a helix-turn-helix (HTH) motif and a carboxy-terminal domain, named Regulation of Amino acid Metabolism (RAM) [20], which is responsible for protein multimerization and cofactor binding [8]. This RAM domain forms an $\alpha \beta$ sandwich fold having an antiparallel $\beta$ sheet composed of four strands "sandwiched" between two $\alpha$ helices. It has been observed that, in vitro, archaeal Lrp-like proteins associate into several multimeric forms via $\beta$ strand exchange in the RAM domain $[10,17,21-28]$. Oligomerization is a prerequisite for formation of the cofactor binding pocket. Furthermore, cofactor binding induces conformational changes that in turn could affect oligomerization [11,13].

In S. solfataricus, a crenarchaeal model organism, three Lrp-like TFs have been studied experimentally: LysM $[10,16]$, Ss-Lrp [25] and Ss-LrpB $[9,27,29]$, the latter being one of the best characterized Lrp-like regulators in archaea. Ss-LrpB performs both positive and negative autoregulation in a concentration-dependent manner [30]. Moreover, gene expression analysis in an $S s-\operatorname{lrpB}$ deletion strain demonstrates that Ss-LrpB acts as an activator on its neighbouring target operon/genes encoding a pyruvate ferredoxin oxidoreductase ( $\operatorname{por} D A B)$ and two putative permeases (Sso2126, Sso2127) [9].

At its target promoter regions, Ss-LrpB binds either a single or multiple, regularly spaced, binding sites harbouring a conserved motif [9,29]. Each binding site is contacted by an Ss-LrpB dimer [27]. In the control region of its own gene (Sso2131), three Ss-LrpB dimers bind cooperatively to juxtaposed sites [31]. Occupation of all three sites results in strong DNA deformations and even DNA wrapping [27]. Based on the 15-bp palindromic consensus sequence 5'-TTGCAAAATTTGCA A-3', the sequence specificity of Ss-LrpB binding was analyzed by saturation mutagenesis [32].

Despite extensive knowledge of the in vitro DNAbinding properties of Ss-LrpB, nothing is known yet about its in vivo binding behaviour and furthermore, it is unclear whether Ss-LrpB is a local or global acting TF. In this work, we investigate Ss-LrpB binding in an in vivo context by performing chromatin immunoprecipitation combined with DNA microarray analysis (ChIP-chip). Besides merely identifying in vivo binding sites, we perform an extensive comparative analysis of in vitro, in vivo and in silico binding, exploiting the knowledge of the DNA-binding specificity model. By combining in vivo binding data with gene expression analysis, we provide new insights into the biological functions of Ss-LrpB, which go beyond direct transcription regulation.

\section{Methods}

\section{Strains and culture conditions}

S. solfataricus P2 (DSM1617), PBL2025 [33] and Ss-lrpB:: lacS [9] strains were grown aerobically at $80^{\circ} \mathrm{C}$ in Brock basic medium supplemented with $0.1 \%$ tryptone as a carbon and energy source [34]. Escherichia coli strain DH5 $\alpha$ was used for all cloning and plasmid propagation purposes. E. coli strain BL21(DE3) was used as a host for protein overexpression.

\section{Chromatin immunoprecipitation}

Each chromatin immunoprecipitation (ChIP) sample was prepared from a $200 \mathrm{ml}$ culture of S. solfataricus P2 at mid-exponential growth phase. The entire ChIP procedure, from collecting cells to obtaining amplified enriched and input DNA ready to use for microarray hybridization was performed as described [35]. In contrast to our previous work, in which a single ChIP sample was analyzed [35], we prepared and analyzed three biological replicate Ss-LrpB-specific ChIP samples. Prior to microarray hybridization analysis, samples were analyzed for enrichment relative to input DNA, which is total DNA extracted before immunoprecipitation, by quantitative PCR (qPCR) with primers specific for the Ss-lrpB control region (Additional file 1: Dataset S1). Furthermore, after ChIP-chip, enrichment of newly discovered binding regions was quantified similarly by qPCR. All primers are listed in Additional file 2: Table S1. qPCR was performed with a My-iQ Single Colour Real-Time PCR System (Bio-Rad) as described before [35], in triplicate and normalized to reference DNA, a non-related sequence fragment amplified from $E$. coli gDNA and spiked at $30 \mathrm{ng} /$ sample before sonication.

\section{Microarray hybridization and data analysis}

Microarray hybridizations were performed with customized $385 \mathrm{~K}$ high-density tiling arrays by NimbleGen (Roche) as described previously [35]. ChIP input and output samples were labelled with $\mathrm{Cy} 3$ and $\mathrm{Cy} 5$, respectively. Each probe occured twice on each array, yielding technical duplicate measurements for all samples. Microarray data analysis was performed using an extended version of the program described by Toedling and Huber [36], which uses the Ringo package of R-Bioconductor. The source code of the extended program is available via http://micr. vub.ac.be. It includes importing the data, data quality assessment, preprocessing of the data and identifying ChIPenriched regions in a similar way as described in [16], with 
a threshold of 1 on the normalized $\log 2$ ratios. ChIPenriched regions were selected as being co-associated when a LysM binding region overlapped at least partially with an extended Ss-LrpB ChIP-enriched region.

\section{Binding motif predictions}

Using a binding energy based position weight matrix of Ss-LrpB [32], binding motifs were predicted over (i) the entire S. solfataricus P2 genome sequence, (ii) the genomic regions comprising $200 \mathrm{bp}$ upstream of the ORF start, and (iii) the ChIP-enriched regions. The latter was also performed using the MEME suite [37]. Corresponding theoretical binding dissociation equilibrium constants $\left(K_{\mathrm{D}} \mathrm{s}\right)$ were calculated as well.

\section{DNA manipulations}

Genomic DNA (gDNA) was prepared from a $10 \mathrm{ml} S$. solfataricus P2 culture grown until late exponential growth phase as described before [25]. Plasmid DNA was extracted from $E$. coli DH5 $\alpha$ strains using a miniprep kit (Qiagen). For cloning of promoter regions, PCRs were performed with the FastStart High Fidelity PCR System (Roche Applied Sciences), S. solfataricus gDNA as a template and oligonucleotides (Sigma-Aldrich) as listed in Additional file 2: Table S1. In case of the $g p T-1 / m t a P$ promoter region, the oligonucleotides contained BamHI and PstI restriction sites, allowing subsequent cloning into the ampicillin resistant vector pUC18 [38]. In case of the Sso0049 promoter region, the fragment was cloned into the pCR2.1-TOPO vector by using a TOPO TA cloning kit (Invitrogen). Individual binding sites were cloned in pBend 2 by annealing two complementary oligonucleotides and ligating them into $\mathrm{XbaI}-$ restricted vector.

\section{Electrophoretic mobility shift and footprinting assays}

Recombinant non-tagged Ss-LrpB and LysM were overexpressed in E. coli BL21(DE3) and purified as described previously [16,27]. Electrophoretic Mobility Shift Assays (EMSAs) were performed with gel-purified 5 '-end ${ }^{32} \mathrm{P}$-labelled PCR fragments generated by using ReadyMix Taq PCR Mix (Sigma-Aldrich). For validation of in vitro binding to in vivo identified binding regions, S. solfataricus P2 gDNA was used as a template, whereas for study of in vitro binding to the promoter regions and individual sites of $m$ taP and Sso0049, plasmid DNA was used as a template. The sequences of all oligonucleotides (Sigma-Aldrich) are provided in Table S1 (Additional file 2). The experiments were performed as described previously [22] using LrpB binding buffer [27]. The $K_{D}$ value for binding to the CRISPR4 target was obtained using the Densitometric Image Analysis Software, available at http://micr.vub.ac. be. DNase I and 'in gel' copper-phenantroline ( $\mathrm{Cu}-\mathrm{OP})$ footprinting assays were executed as described [22,29].
Reference ladders were generated by chemical sequencing [39].

\section{Quantitative reverse transcription PCR (qRT-PCR)}

For qRT-PCR analysis, $2 \mathrm{ml}$ of an exponentially grown $S$. solfataricus PBL2025 or Ss-lrpB::lacS culture was mixed with $4 \mathrm{ml}$ RNAprotect Bacteria Reagent (Qiagen) and centrifuged. Pelleted cells were subsequently lysed and RNA was extracted with the SV Total RNA Isolation System (Promega). To prevent gDNA contamination, RNA samples were treated with DNase I using the TURBO DNA-free kit (Invitrogen) according to manufacturer's instructions. First-strand cDNA was synthesized from $1 \mu \mathrm{g}$ RNA with SuperScript III First-Strand Synthesis SuperMix kit (Invitrogen). Primers (Additional file 2: Table S1) were designed with Primer3 software [40] and purchased at Sigma-Aldrich. qPCR was performed in a Bio-Rad iCycler with each reaction mixture containing $12.5 \mu \mathrm{l}$ iQ SYBR Green Supermix (Bio-Rad), forward and reverse primers and $1 \mu \mathrm{l}$ 100-fold diluted cDNA. The amplification protocol was as follows: initial denaturation at $95^{\circ} \mathrm{C}$ during 3 minutes, 40 cycles of $95^{\circ} \mathrm{C}$ during 10 seconds and $55^{\circ} \mathrm{C}$ during 30 seconds and one cycle of $95^{\circ} \mathrm{C}$ during 1 minute and $55^{\circ} \mathrm{C}$ during 1 minute. The melt curve analysis demonstrated absence of primerdimer formation. All qRT-PCR assays were carried out in technical duplicate for at least four biological replicates and with a no-template and a no-RT control. Quantification cycles $\left(\mathrm{C}_{\mathrm{q}} \mathrm{s}\right)$ were determined with Bio-Rad iQ5 software and mean relative gene expression ratios including standard deviations were calculated with the $2\left(-\Delta \Delta C_{t}\right)$ method [41]. Normalization was with respect to the expression of $t b p$, which was comparable in both strains. Data were subjected to t-test analysis using the statistical package Prism 6.0 (GraphPad).

\section{Results}

\section{Genome-wide binding profile of Ss-LrpB}

To study genome-wide association of Ss-LrpB in vivo, we applied nanobody ${ }^{\circ}$-based ChIP-chip on exponentially growing $S$. solfataricus cells. Previously, we have used Ss-LrpB-specific nanobodies ${ }^{\oplus}$ as a proof of principle for the utilization of this class of antibodies in ChIP technology [35]. In contrast to this first study, involving a single immunoprecipitation, we now performed replicate experiments with three independent biological samples. In addition, a nanobody ${ }^{\odot}$ recognizing a target that is absent in S. solfataricus cells was used in a mock ChIP experiment. Only regions exhibiting more than 2-fold enrichment in ChIP versus input DNA in all three SsLrpB-specific ChIP replicates, but not in the mock ChIP sample, were considered to be bound significantly to SsLrpB. In total 37 genomic regions, distributed over the entire genome, were identified (Figure 1A; Additional file 1: 


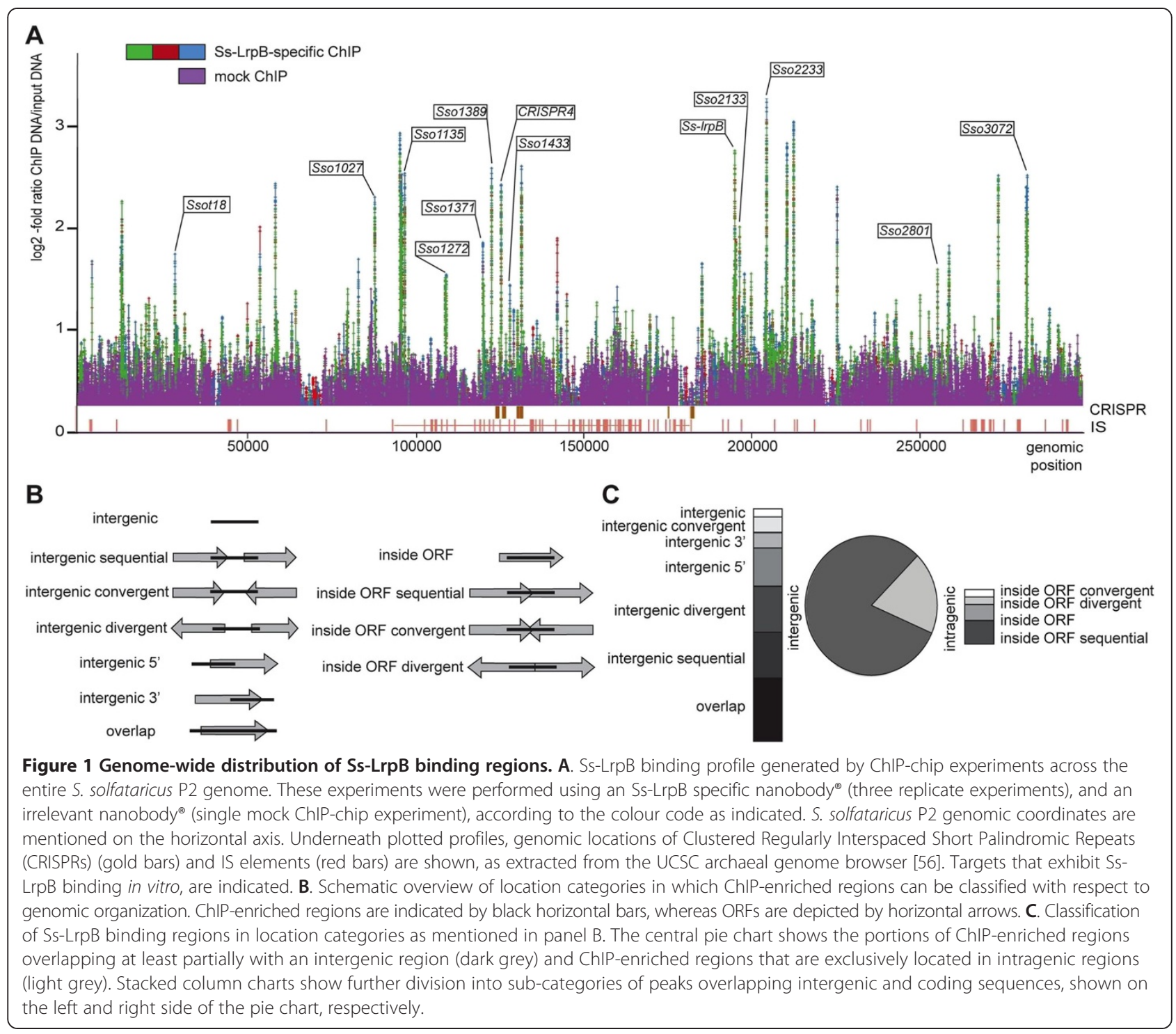

Dataset S1). Enrichment fold ratios ranged from 2.2 to 10.8 and were further validated by qPCR experiments, which generally yielded higher enrichment fold ratios than DNA microarray analysis, demonstrating a higher sensitivity. Nevertheless, both datasets exhibit a positive correlation (Additional file 3: Figure S1).

The genes that are overlapping or closest to the 37 ChIP peaks belong to various functional classes such as amino acid metabolism, energy metabolism, central metabolism and transport (Additional file 4: Figure S2). We also classified peaks according to their location with respect to open reading frames (ORFs) (Figure 1B and C; Additional file 1: Dataset S1). Although the majority of identified ChIP peaks are overlapping or located in an intergenic region (81\%), many of these locations are unusual for a typical TF and are distant from promoters, as also demonstrated by the large distances between most peak centers and the closest experimentally determined transcription start sites (TSSs) [42] (Additional file 1: Dataset S1). Several peaks, classified as "overlap", (partially) cover two or more ORFs (Additional file 5: Figure S3).

\section{In vitro analysis of Ss-LrpB binding to in vivo identified binding regions}

We performed an EMSA screen for all 36 newly identified Ss-LrpB-bound genomic regions to verify whether these target regions also interact with purified protein in vitro (Figure 2A; Additional file 6: Figure S4). Fragment sizes ranged from 200 to $700 \mathrm{bp}$ and were designed to contain the best potential Ss-LrpB binding motif, predicted either using the binding energy weighted position matrix [32] or with the MEME suite (Additional file 1: Dataset S1). Twelve fragments displayed a concentration-dependent 


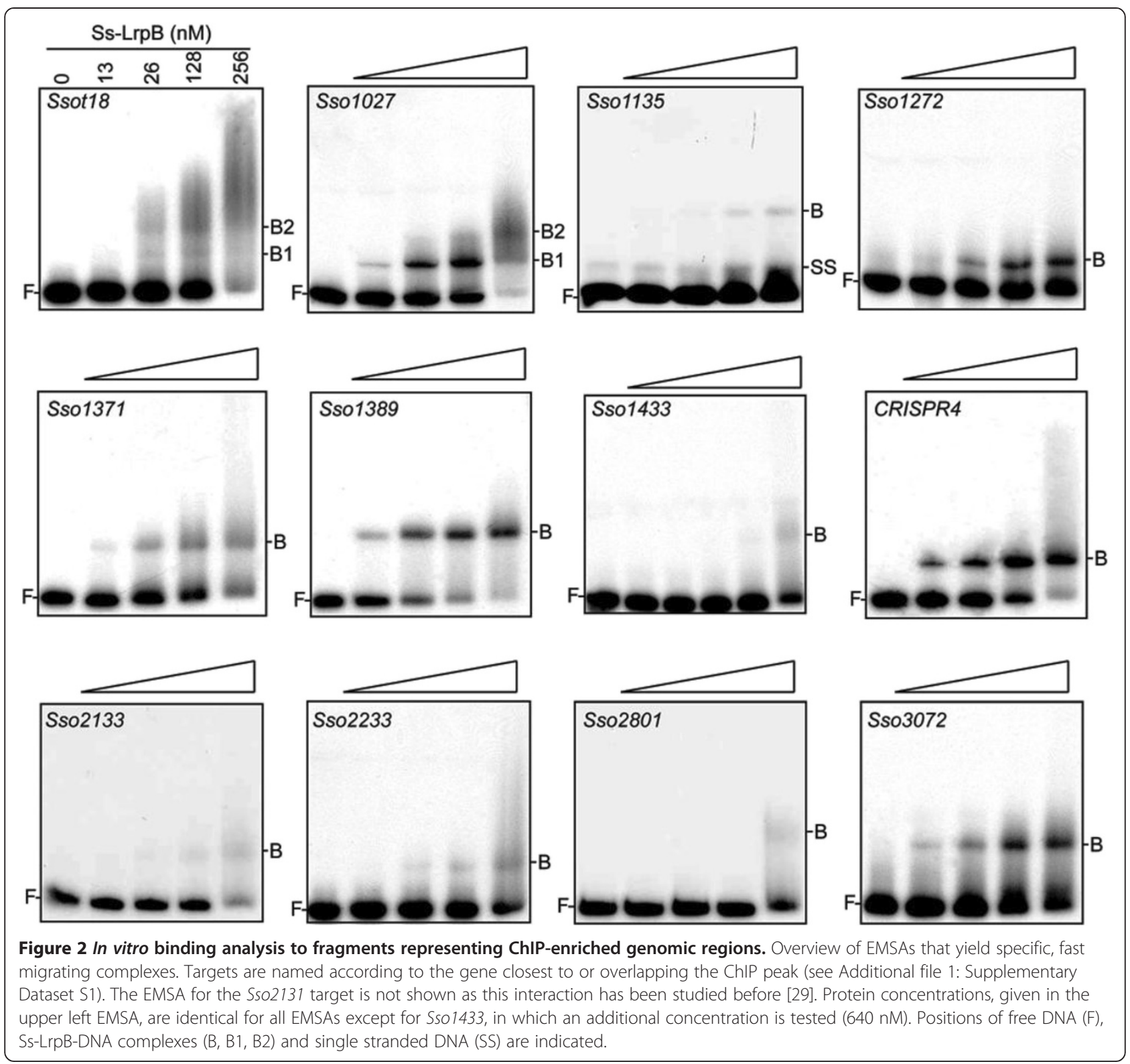

formation of one or two specific nucleoprotein complexes (Figure 2A) (Additional file 7: Table S2). The fast relative mobility of these complexes suggests that they contain one or maximally two Ss-LrpB dimers, rather than multiple cooperatively binding protein molecules. EMSAs performed with the other 24 fragments did not show any binding, or were indicative of unstable and nonspecific low-affinity binding resulting in smearing and/or the formation of higher-order complexes that remain in the well (Additional file 6: Figure S4).

It is notable that most of the newly identified Ss-LrpB binding sites that are directly bound, both in vitro and in vivo, are located in a highly variable region of the genome comprising multiple insertion sequence (IS) elements (Figure 1A). Furthermore, most of these SsLrpB binding sites are in the direct neighbourhood of an IS element. For all 12 in vitro bound Ss-LrpB targets, binding occurs with a lower affinity as compared to the control region of the $S s-\operatorname{lrpB}$ gene itself [29] (Figure 2A). For example, the CRISPR4 target, one of the higheraffinity targets, is bound with an equilibrium dissociation constant $\left(\mathrm{K}_{\mathrm{D}}\right)$ of $63 \pm 5 \mathrm{nM}$. The predictive power of the binding energy weight model appears to be limited as several predicted binding motifs have low theoretical $K_{\mathrm{D}} \mathrm{S}$ but nevertheless did not exhibit a specific interaction in vitro and vice versa, as several specifically bound motifs have high theoretical $\mathrm{K}_{\mathrm{D}} \mathrm{s}$ (Additional file 7: Table S2). 


\section{In vivo binding to Ss-IrpB, porDAB, Sso2126 and Sso2127 operators}

Upon zooming into the profile at the $S s-\operatorname{lrpB}$ genomic region containing the regulatory target genes identified previously [9], we observed binding at all target promoters although signals in the Sso2126, Sso2127 and porDAB promoter regions did not reach the 2-fold enrichment threshold level in all replicates (Figure 3). Averaged peak heights appear to correlate with both in vitro binding affinity and number of binding sites in the respective promoter/operator $(\mathrm{p} / \mathrm{o})$ regions (binding affinities/number of binding sites can be ranked as follows: $\mathrm{p} / \mathrm{oSs}$ - $\operatorname{lrp} B>\mathrm{p} /$ opor$D A B>$ p/oSso $2127>$ p/oSso2126 [9,29]). Furthermore, for the targets porDAB, Sso2126 and Sso2127 this correlation can be extended to the level of activation [9].

An active copy of ISC1078 (containing a transposase encoded by Sso2132) is located downstream of $S s-\operatorname{lrpB}$ with respect to genome sequence orientation $[9,43]$. However, the steep decline in ChIP enrichment for the probes representing the concerned IS sequence (Figure 3) and further PCR analysis (Additional file 8: Figure S5) demonstrated the absence of this element in a large subpopulation of the cells that were subjected to ChIP.

Interestingly, the EMSA screen also resulted in a further unraveling of the $S s-\operatorname{lrp} B$ operator for autoregulation: a fragment comprising the sequence between the insertion site of ISC1027 and the Sso2133 ( $g l p K-2)$ promoter results in the formation of a single specific complex (Figure 2A, Sso2133 target). This observation implies sequencespecific recognition of another Ss-LrpB binding motif, located downstream (with respect to genome sequence orientation) of Box3 with a center-to-center distance of 174 bp (Additional file 9: Figure S6). Possibly, this site, referred to as Box6, is an auxiliary operator site that supports binding to the main high-affinity operator sites, besides the intragenic Box4 and Box5, which were identified previously as secondary operator sites (Additional file 9: Figure S6) [35].

\section{Ss-LrpB binds in CRISPR A and B leader regions}

Ss-LrpB is associated through direct high-affinity binding with two clusters of regularly interspaced short palindromic repeats (CRISPR) loci, which are essential elements of an adaptive immunity system against viruses and other invading genetic elements. The concerned CRISPR loci, A and B, are paired family II CRISPRs sharing the same repeat sequence and are bordered by quasi-identical leader regions containing the elements to initiate and control transcription of the long pre-crRNA [44]. Ss-LrpB binding regions, previously annotated as "Sso1389" and "CRISPR4", overlap the 502-bp long CRISPR A and B leader regions, respectively (Figure 4A). 'In gel' $\mathrm{Cu}-\mathrm{OP}$ footprinting with a DNA probe representing the CRISPR B leader sequence clearly revealed Ss-LrpB-mediated protection of a stretch of about 14 nucleotides (nt) corresponding to a relatively well conserved binding motif in the promoter-proximal part of the leader (Figures $4 \mathrm{~B}$ and $\mathrm{C}$ ).

Given the high sequence identity between the CRISPR $A$ and $B$ leader regions, it is assumed that binding occurs at the corresponding site with the same sequence in the CRISPR A leader (Figure 4D). The center of the identified Ss-LrpB binding site is located $116 / 117$ bp upstream of the main pre-crRNA TSS [42] in the first CRISPR repeat sequence, which is preceded by a strong promoter. This leads us to hypothesize that Ss-LrpB affects transcription of pre-crRNA through interaction with the basal transcription machinery.

\section{Permissivity of the genome for Ss-LrpB binding}

Using the binding energy position weight matrix, we searched the entire S. solfataricus P2 genome for additional

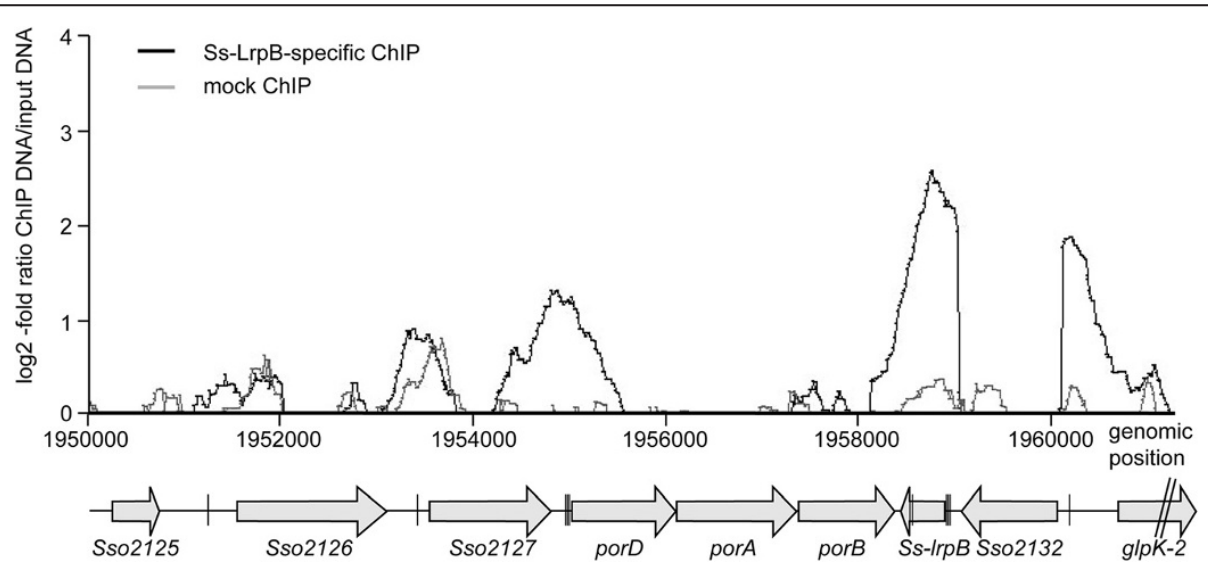

Figure 3 Zoomed average ChIP-chip binding profile in the Ss-IrpB (Sso2131) genomic region. Below the profile, relative locations of genes and characterized Ss-LrpB binding sites $[9,29]$ are shown in alignment with genomic positions. ORFs are indicated as horizontal arrows, whereas Ss-LrpB binding sites are depicted as vertical lines. 


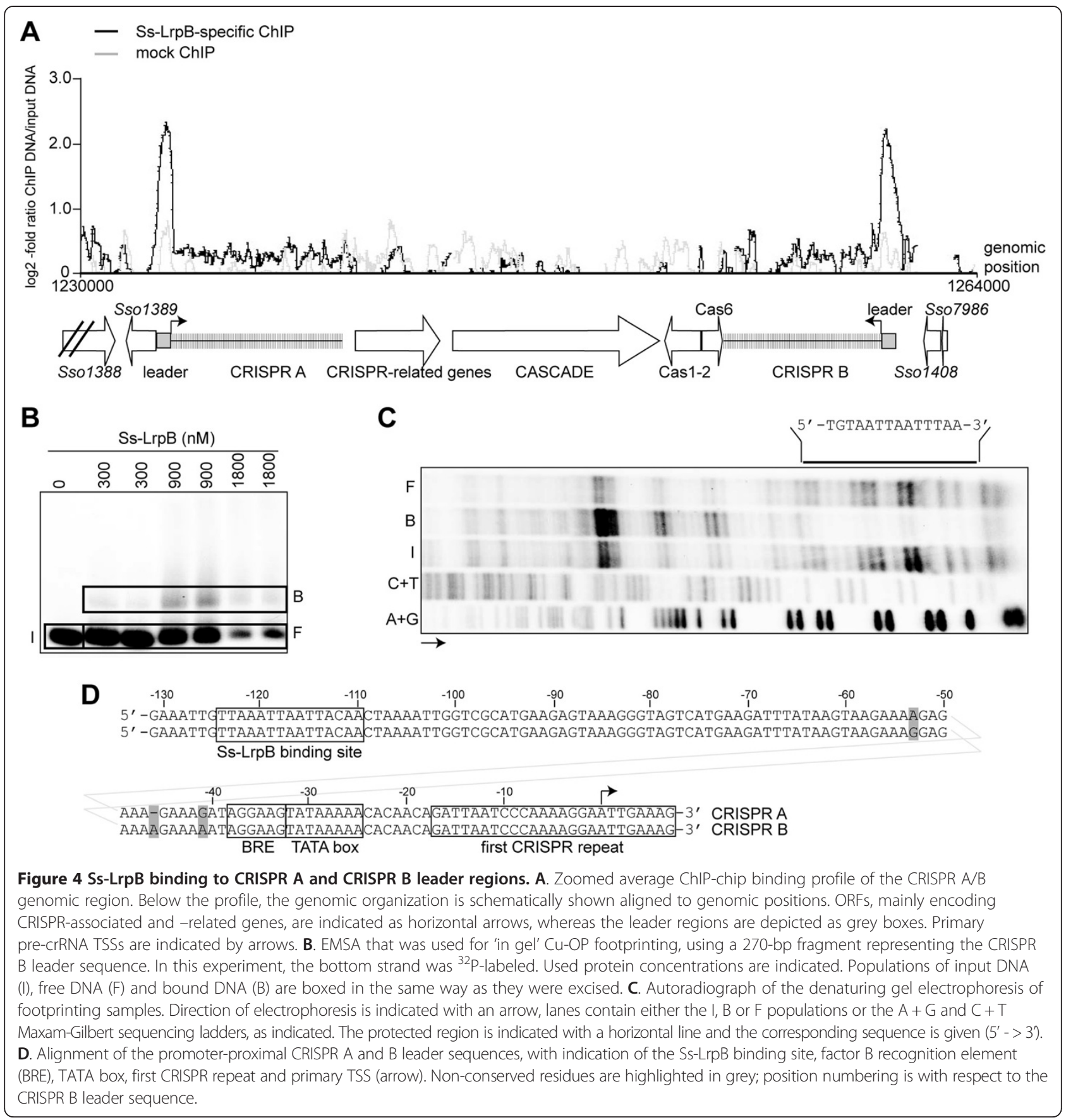

potential Ss-LrpB binding motifs. Setting the threshold for the theoretical $K_{D}$ at $14 \mu \mathrm{M}$, a value still significantly lower than the average theoretical $K_{D}$ calculated for the novel identified Ss-LrpB sites that are bound both in vivo and in vitro $(290 \mu \mathrm{M})$, we detected 519 motifs of which 100 are located in regions 200 bp upstream of translational starts (Additional file 10: Table S3). Some of these motifs are canonical Ss-LrpB binding motifs located at appropriate distances from promoters to have the ability to exert regulation. Nevertheless, binding is absent at these locations in vivo.

We selected two examples to illustrate this disagreement between binding in vitro and in vivo (Figure 5; Additional file 11: Figure S7). The promoter region of Sso0049, encoding an unknown protein, contains a canonical binding motif (5'-TTGTAATTTTTTCAA-3') that is identical to the high-affinity Box 1 of the $S s-\operatorname{lrpB}$ operator 5'-TTGTAATTTTTACAA-3' with the exception 


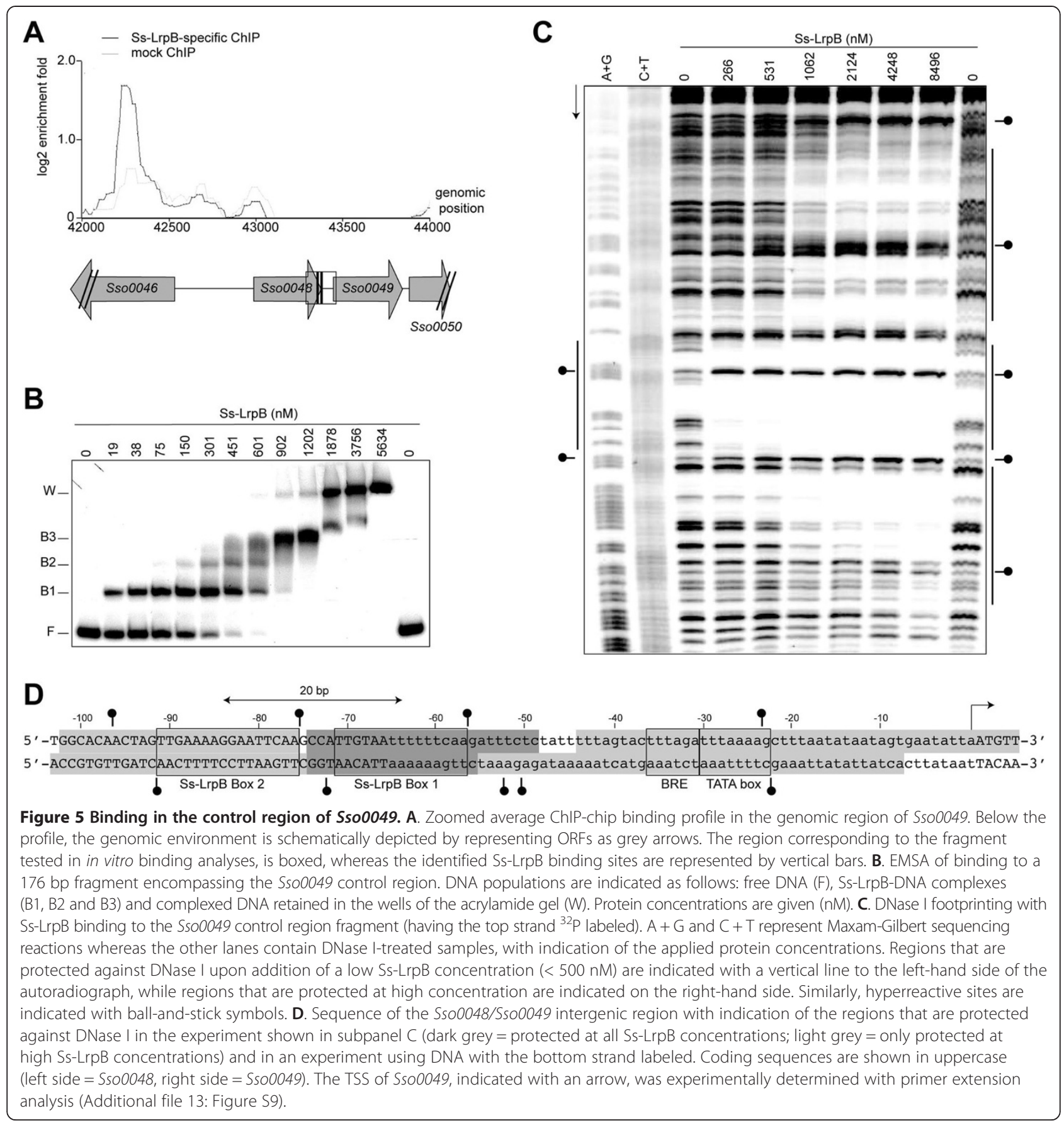

of one $\mathrm{A} \rightarrow \mathrm{T}$ substitution at a less critical position. An EMSA probing binding of Ss-LrpB to a p/oSso0049 fragment revealed the formation of three distinct proteinDNA complexes (Figure 5B). DNase I footprinting showed that it is indeed the predicted binding motif referred to as Box 1 that is bound at low protein concentration and is most likely protected in complex B1 in the EMSA (Figures 5B and C). Furthermore, an EMSA using a fragment containing solely the Sso0049 Box 1 confirmed a high-affinity interaction $\left(\mathrm{K}_{\mathrm{D}} \approx 150 \mathrm{nM}\right.$; Additional file 12 : Figure S8). At higher Ss-LrpB concentrations, DNase I protection in the $\mathrm{p} / \mathrm{oSso0049}$ fragment was extended both downstream and upstream of Box 1. Upon manual inspection of the sequence, we identified an additional binding motif (Box 2) with a center-to-center-distance of $20 \mathrm{bp}$ upstream of Box 1 (Figure 5C). Despite the high-affinity, cooperative binding to multiple binding sites in vitro, no enrichment of this genomic region has been detected 
in the ChIP-chip assay (Figure 5A). Notably, Ss-LrpB is associated with the genome about $1 \mathrm{~kb}$ upstream of the Sso0049 control region in the ORF of Sso0046. This observation suggests that absence of Ss-LrpB at p/oSso0049 is not caused by limited diffusion of the TF throughout the cell but rather to an inaccessibility of chromatin or the DNA sequence itself at this locus.

A similar discrepancy between in vitro and in vivo binding was shown to exist for the intergenic promoter region shared between the divergently transcribed Sso2342, encoding a purine phosphoribosyltransferase $(g p T-1)$, and Sso2343, encoding a 5'-methylthioadenosine phosphorylase $(m t a P)$ (Additional file 11: Figure S7; Additional file 12: Figure S8; Additional file 13: Figure S9). Altogether, these observations demonstrate that the target DNA sites within the $S$. solfataricus genome are not entirely permissive for Ss-LrpB binding.

\section{Overlap between Ss-LrpB and LysM binding profiles}

S. solfataricus possesses additional Lrp-like TFs, such as the lysine-responsive LysM. We compared the Ss-LrpB binding profile to the locations of the LysM binding regions mapped previously [16] and observed a significant overlap: 29 of the 37 Ss-LrpB binding regions were also associated with LysM (Figure 6A; Table 1). Of note, no cross-reactivity of Ss-LrpB- and LysM-specific nanobodies with other Lrp-type proteins has ever been observed $[16,35]$. Zoomed binding profiles for both TFs are highly similar, which is a striking observation given that both profiles were recorded in different growth conditions (sucrose-supplemented for LysM-specific ChIP versus tryptone-supplemented medium for Ss-LrpB-specific ChIP) (Figure 6B).

The known regulatory targets of Ss-LrpB, Sso2126, Sso 2127 and porDAB, are not co-bound by LysM, in contrast to most of the newly discovered low-affinity SsLrpB binding targets. Conversely, the main local regulatory target of LysM, the lys WXJK operon for lysine biosynthesis, is also bound by Ss-LrpB. To distinguish between (i) a mutually exclusive binding of either Ss-LrpB or LysM at a particular target in a subpopulation of cells, or (ii) a situation where the proteins bind as a co-complex to this target, we compared in vitro and in silico binding characteristics for these targets (Table 1). Shared binding regions could be categorized in three classes: (i) binding regions that contain an Ss-LrpB binding motif and exhibit binding to Ss-LrpB but not LysM in vitro (class I); (ii) binding regions that contain a LysM binding motif and exhibit (predicted) binding to LysM but not Ss-LrpB in vitro (class II) and (iii) binding regions that do not contain an Ss-LrpB or LysM binding motif and do not interact with any of the two proteins in vitro (class III). There is a perfect inverse correlation pattern between the presence of a bona fide Ss-LrpB or LysM binding motif suggesting that the TFs are co-localized through protein-protein interaction and that only one of the protein partners directly interacts with the DNA.

We further investigated the simultaneous interaction of LysM and Ss-LrpB to one of the co-bound targets, Ssot28, in an in vitro assay (Figure 6C). Whereas SsLrpB does not form specific complexes with this target (Additional file 6: Figure S4), LysM forms a single complex by binding to a site located close to the promoter of the glutamate synthase $(g l t B)$ gene [16]. EMSA analysis demonstrated that the addition of Ss-LrpB to reaction mixtures containing LysM and the DNA stimulated slightly the complex formation (Figure 6C). Furthermore, the addition of Ss-LrpB-specific antibodies resulted in a clear supershift of the complex. These observations suggest that Ss-LrpB is present in the nucleoprotein complex, despite that it is unable to interact with the DNA fragment by itself.

\section{Gene expression analysis of transcripts associated with Ss-LrpB binding regions}

To determine whether the identified binding events cause transcription regulation of neighbouring genes, we investigated the effect of deleting $S s-\operatorname{lrp} B$ on the expression of a wide selection of potential target genes by quantitative reverse transcriptase PCR (qRT-PCR) (Figure 7). Some of these genes were associated with direct Ss-LrpB binding (class I), others with indirect binding (class II, III and IV), yet others with co-binding of Ss-LrpB and LysM (class I, II and III) (for a definition of the classes, see legend of Figure 7). For some of them, binding occurs relatively close to the promoter whereas for other genes the binding is intragenic and far away from the closest promoter region (e.g. Sso2233). With the exception of the CRISPR B pre-crRNA, deletion of Ss-lrpB did not significantly affect the expression of any of these tested target genes. We have also confirmed that the TF does not significantly affect the expression of Sso0049, which contains high-affinity Ss-LrpB binding sites in its promoter region that are however not associated with Ss-LrpB in vivo.

The expression of CRISPR B pre-crRNA is moderately downregulated (2-fold) in the Ss-lrpB::lacS strain in comparison to the isogenic WT, indicating an Ss-LrpBmediated activation. It is assumed that a similar regulation will be exerted at the CRISPR A locus. In conclusion, SsLrpB is involved in CRISPR regulation whereas the other identified binding events appear to occur without apparent regulation under our conditions of growth.

\section{Discussion}

Our genome-wide localization study has revealed the association of Ss-LrpB with at least 37 loci in the $S$. solfataricus genome. A subset of these in vivo Ss-LrpB- 


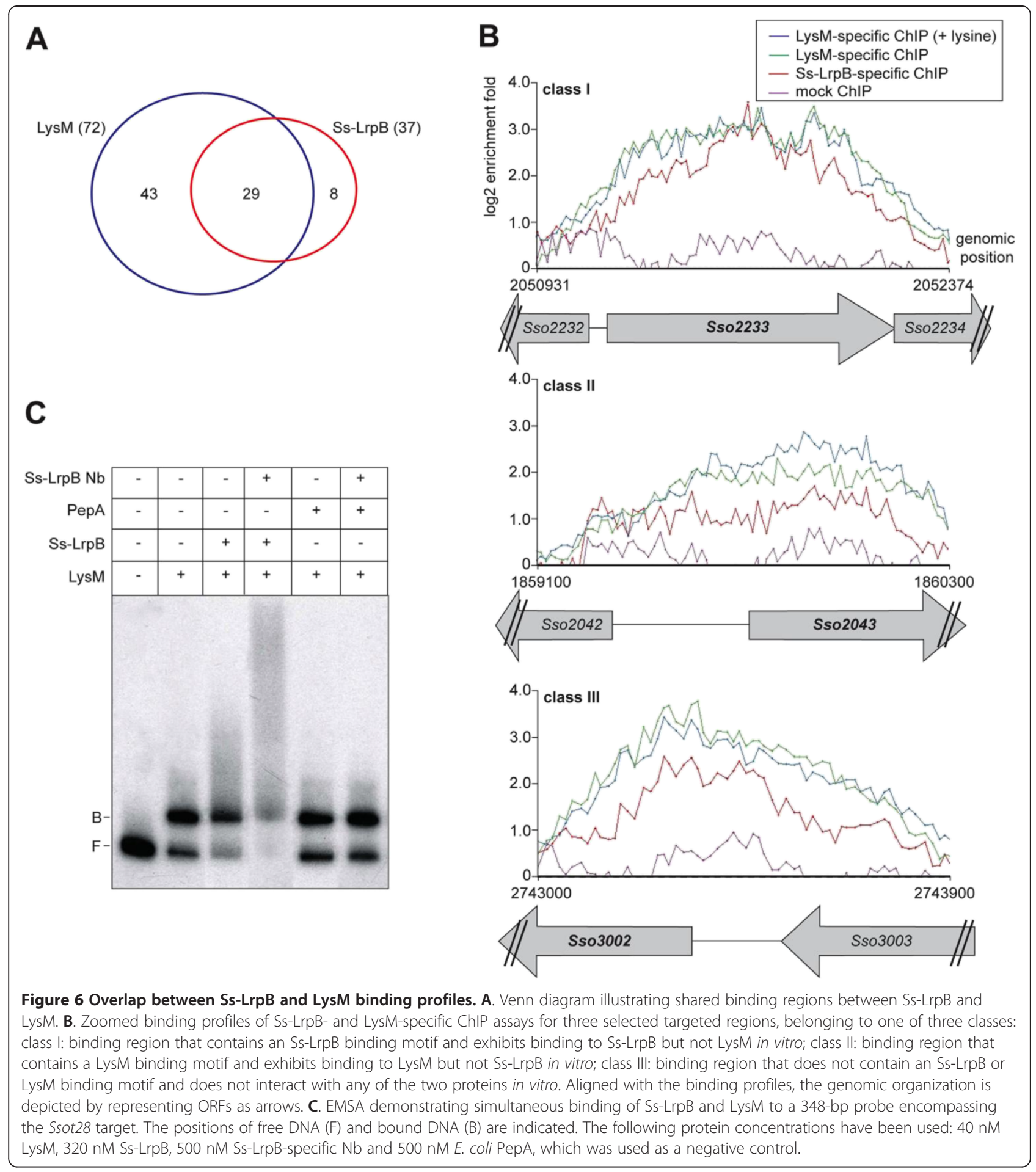

targeted sites is clearly validated to be bound with this pure TF in vitro and to contain a bona fide sequence motif. Obviously, the well-established, high sequence specificity of Ss-LrpB [32] is responsible for the complex formation at these sites. However, computational analysis with a binding energy based position weight matrix of the $S$. solfataricus genome demonstrated a vast overrepresentation of appropriate sequence motifs of which only a very small subset seems to be actually bound in vivo. A high number of false negative signals in the ChIP-chip analysis, e.g. due to a too stringent threshold, is a possible explanation for the observed lack of in vivo binding at predicted motifs. However, a closer investigation of the binding profiles at loci containing 
Table 1 Overview of the Ss-LrpB-specific ChIP-enriched regions that are also enriched in LysM-specific ChIP-chip analysis

\begin{tabular}{|c|c|c|c|c|c|c|}
\hline $\begin{array}{l}\text { Target } \\
\text { name }\end{array}$ & $\begin{array}{c}\text { Genomic coordinate } \\
\text { peak start }\end{array}$ & $\begin{array}{c}\text { Genomic coordinate } \\
\text { peak stop }\end{array}$ & $\begin{array}{l}\text { Relative position to } \\
\text { LysM-specific peak }\end{array}$ & $\begin{array}{l}\text { Presence of Ss-LrpB } \\
\text { binding motif }\end{array}$ & $\begin{array}{l}\text { Presence of LysM } \\
\text { binding motif }\end{array}$ & Class \\
\hline Sso0154 & 129616 & 130620 & Inside & - & - & III \\
\hline Sso5317 & 131930 & 133008 & Including & - & + & $\|$ \\
\hline Ssot18 & 290428 & 291131 & Inside & + & - & 1 \\
\hline Ssot28 & 589572 & 590362 & overlap (89\%) & - & + & $\|$ \\
\hline S506904 & 835210 & 835839 & Inside & - & + & $\|$ \\
\hline Sso1027 & 885479 & 886771 & Inside & + & - & I \\
\hline Ssol114 & 960343 & 961574 & Including & - & $-*$ & III \\
\hline Ssol118 & 964702 & 966378 & Including & - & $-*$ & III \\
\hline Sso1135 & 974250 & 975551 & overlap (99\%) & + & $-*$ & I \\
\hline Sso1272 & 1095398 & 1097098 & Inside & + & $-*$ & I \\
\hline Sso1371 & 1206614 & 1207226 & overlap (97\%) & + & $-*$ & । \\
\hline Sso1389 & 1232759 & 1233642 & overlap (99\%) & + & $-*$ & I \\
\hline CRISPR4 & 1260282 & 1261337 & Including & + & $-*$ & I \\
\hline Sso1433 & 1286420 & 1286928 & Inside & + & $-*$ & I \\
\hline Sso1463 & 1321798 & 1323084 & overlap (98\%) & - & $-*$ & III \\
\hline Sso1890 & 1705187 & 1705830 & Inside & - & $-*$ & III \\
\hline Sso2043 & 1859092 & 1860291 & overlap (75\%) & - & + & $\|$ \\
\hline Sso2159 & 1985046 & 1985784 & Inside & - & $-*$ & III \\
\hline Sso2233 & 2050931 & 2052374 & Including & + & $-*$ & I \\
\hline Sso2289 & 2099312 & 2099902 & Inside & - & $-*$ & III \\
\hline S502309 & 2111358 & 2112389 & Inside & - & $-*$ & III \\
\hline Sso2310 & 2113136 & 2114378 & overlap (93\% ) & - & $-*$ & III \\
\hline Sso2334 & 2132622 & 2134455 & Including & - & + & $\|$ \\
\hline Sso2404 & 2187776 & 2188318 & Inside & - & $-*$ & III \\
\hline Sso2678 & 2437317 & 2437768 & overlap (96\%) & - & $-*$ & III \\
\hline Sso2801 & 2561656 & 2562152 & overlap (57\%) & - & $-*$ & III \\
\hline Sso2833 & 2594520 & 2595831 & overlap (96\%) & - & $-*$ & III \\
\hline Sso3002 & 2742947 & 2743947 & Including & - & $-*$ & III \\
\hline Sso3072 & 2827204 & 2828448 & overlap (94\%) & + & $-*$ & I \\
\hline
\end{tabular}

The presence of an Ss-LrpB binding motif (measured by EMSA) or a LysM binding motif (either measured by EMSA or predicted in silico (indicated by an asterisk) [16]) is indicated. Classes are defined as follows: class I: binding region that contains an Ss-LrpB binding motif and exhibits binding to Ss-LrpB but not LysM in vitro; class II: binding region that contains a LysM binding motif and exhibits binding to LysM but not Ss-LrpB in vitro; class III: binding region that does not contain an Ss-LrpB or LysM binding motif and does not interact with any of the two proteins in vitro. Ranking is according to genomic location.

multiple high-affinity binding motifs (promoter regions of Sso0049 and mtaP) confirmed complete absence of Ss-LrpB-specific enrichment in these regions. Therefore, we conclude that the intrinsic DNA-binding sequence specificity is a poor predictor of binding in vivo under our culture conditions of $S$. solfataricus and that additional factors are involved in determining site selectivity and occupancy in vivo.

In vivo binding site selectivity could be influenced by the structural landscape of the chromatin that imposes differential genome accessibility on a higher organizational level. Similarly to bacteria, Crenarchaeota have their nucleoid structurally organized by small chromatin proteins [45], however it is unknown how this genome packaging affects TF binding. Possibly, Ss-LrpB binding is restricted by the action of nucleoid associated proteins resulting in differential accessible genomic regions. Apparently, accessibility is facilitated in a highly variable region of the $S$. solfataricus genome with multiple IS elements and low abundance of essential genes. However, there are alternative explanations available for the lack of association at highaffinity binding motifs. For instance, it might be caused by the presence of a co-repressor, ligand or post-translational modification that inhibits Ss-LrpB binding under the used 


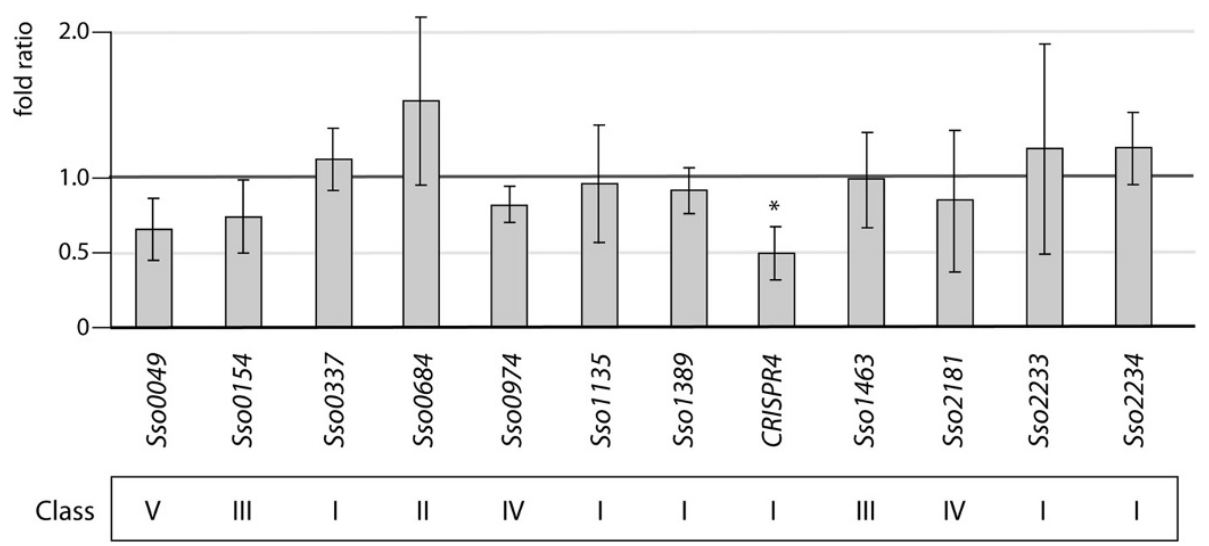

Figure 7 Expression analysis of genes of which the coding regions are located close to a selection of Ss-LrpB binding regions. Tested genes are subdivided into the following classes: class I: gene associated to binding region bound by LysM and Ss-LrpB that contains an Ss-LrpB binding motif and exhibits binding to Ss-LrpB but not LysM in vitro; class II: gene associated to binding region bound by LysM and Ss-LrpB that contains a LysM binding motif and exhibits binding to LysM but not Ss-LrpB in vitro; class III: gene associated to binding region bound by LysM and Ss-LrpB that does not contain an Ss-LrpB or LysM binding motif and does not interact with any of the two proteins in vitro; class IV: gene associated to binding region solely bound by Ss-LrpB in vivo; class V: gene associated to region that is bound by Ss-LrpB in vitro but not in vivo. Relative gene expression ratios in an Ss-IrpB:.:lacS versus PBL2025 strain are normalized against top expression. Values are the average of biological quadruplicates and standard deviations represent the biological variation. An asterisk indicates a P-value of 0.085. All other tested genes render P-values > 0.1, indicating no significant differences in expression. Absence of Ss-IrpB expression in the Ss-IrpB:.IacS strain has been confirmed (fold ratio $=0.0031 \pm 0.0020 ;$ P-value $=0.0001$ ).

culture conditions or, on the contrary, by the absence of a critical ligand in vivo that activates binding and was present in the in vitro binding reaction mixtures, possibly through co-purification after heterologous expression of Ss-LrpB in E. coli. Technical details, such as unstable behavior of the TF-DNA complexes during formaldehyde fixation or sonication, could also lead to certain binding events not being detected.

There is a very low correlation between Ss-LrpB binding and transcription regulation, which appears to be limited to the Sso2126, Sso2127 and porDAB gene targets that were identified previously and to the CRISPR A and B clusters. Furthermore, a significant fraction of binding regions is located at a significant distance from the nearest TSS and associated promoter and/or is even intragenic, an observation made for bacterial [46-49] and for archaeal TFs as well $[16,50]$. The newly discovered genomic targets that contain a binding motif are generally contacted by SsLrpB through non-cooperative low-affinity binding, in contrast to the local gene targets. Low-affinity binding without apparent regulation appears to be universal as it has been observed repeatedly for TFs of M. tuberculosis [51], yeast [52] and Drosophila [53]. However, the biological function of these weak binding sites is still unclear. It has been hypothesized that they could display a subtle regulatory activity, which goes undetected and causes a fine-tuning of gene regulation. In this way, these binding sites alleviate selective pressure on specific loci, namely classical regulatory binding sites, and increase the ability to evolve [53]. An alternative explanation for the biological role of these low-affinity sites is that they might create a biological buffering system that serves as a reservoir to sequester TF molecules, thereby thermodynamically regulating the concentration of freely available protein $[53,54]$. This could be a critical factor for correct functioning of Ss-LrpB, given the limited number of target genes and the cooperative nature of the interaction at these targets.

The observed occupancy levels and regulatory effects of the major regulatory targets (Sso2126, Sso2127, porDAB [9] and CRISPR B) are weak and were most probably recorded in a growth condition yielding a non-regulated "ground state". Possibly, a different, as yet unknown, culturing condition leads to higher occupation and corresponding activation levels of the regulatory target genes. Similarly, some of the newly identified binding sites might mediate regulation of nearby genes under different growth conditions than those in which the binding profile was monitored. The exact functions and substrate specificities of the pyruvate ferredoxine oxidoreductase and the two permeases are unclear although it is tentative to speculate that these proteins function during lactate oxidation or a related metabolic pathway [9]. Indeed, Sso2126 encodes a permease that exhibits homology with bacterial L-lactate permeases and Sso2127 codes for a homolog of halophilic oxalate/formate antiporters. Protein sequence analysis suggests that if Ss-LrpB is bound by an effector molecule, it is a small molecule other than an amino acid [9].

The growth condition that is more relevant for SsLrpB regulation might be a more stressful condition for the cells, given the Ss-LrpB-mediated CRISPR activation. 
It has been demonstrated that expression of CRISPR and CRISPR-associated (CAS) genes is inducible by abiotic and/or biotic stress [55]. The high energetic cost of expressing the long pre-crRNA leads to hypothesize that it is under a complex transcriptional regulation involving multiple regulators, of which we demonstrate that SsLrpB is the first promoter-interacting TF to be characterized in $S$. solfataricus. Co-regulation of porDAB, Sso 2126 and Sso2127 on one hand and the CRISPR clusters on the other hand indicates that there is a possible link between metabolic regulation and immunity defense in S. solfataricus.

Remarkably, the Ss-LrpB and LysM binding profiles display a significant overlap. The detection of the two proteins at the same genomic location in different ChIP-chip profiles could be explained by (i) binding of a heteroprotein complex of LysM and Ss-LrpB to the DNA target or (ii) a heterogeneous occupancy where Ss-LrpB is present on the DNA site in some cells, and LysM on the corresponding DNA site in other cells or (iii) a combination of both possibilities. In the case of these two Lrp-like TFs, the inverse correlation pattern between the presence of a LysM or Ss-LrpB binding motif suggests that they are simultaneously associated as a complex with the target DNA sites in the $S$. solfataricus genome. Furthermore, this coassociation occurs most likely via protein-protein interactions in which only one of the protein partners interacts with DNA, rather than by cooperative interactions between distinct DNA-bound TF molecules. This proposal is supported by our in vitro experiments where Ss-LrpB was shown to be present in the protein-DNA complex although it does not interact with the DNA by itself. For a distinct class ("class III") of binding targets, direct DNA recognition by Ss-LrpB or LysM was clearly absent, suggesting the involvement of additional TFs. Remarkably, we did not observe significant Ss-LrpB-mediated regulation of the major LysM targets to which co-association was observed. Possibly, the presence of Ss-LrpB results only in subtle regulatory effects, fine-tuning the regulatory action of LysM, and the involvement of different partners is partially interchangeable. Our data demonstrate that archaeal Lrp-like TFs interact in vivo, supporting previous data that Pyrococcus Lrp-like TFs tend to form hetero-oligomeric structures in vitro $[11,17]$.

\section{Conclusions}

In conclusion, our genome-wide association study of SsLrpB yields novel insights into its in vivo interactions despite providing only limited additional information on its physiological role. Ss-LrpB interacts with multiple lowaffinity sites throughout the genome without an apparent regulatory purpose and these sites are often associated with IS elements. Furthermore, the TF binds in the CRISPR A and B leader regions and activates expression of pre-crRNA. Ss-LrpB also co-associates with another Lrp-like TF, LysM. Hetero-oligomerization of archaeal Lrp proteins was previously observed in vitro and thus, we provide the first indications of an interplay of two of these factors in vivo. Finally, the absence of Ss-LrpB in vivo on sites carrying a well-predicted binding motif suggests a limited permissivity of the $S$. solfataricus genome for association with its cognate TF.

\section{Availability of supporting data}

All the supporting data are included as additional files.

\section{Additional files}

Additional file 1: Dataset S1. Overview of all ChIP-enriched regions
identified in the study, with indication of details of GPCR and EMSA ex-
periments for validation.

Additional file 2: Table S1. List of oligonucleotide sequences used in this work.

Additional file 3: Figure S1. Statistical analysis of Ss-LrpB ChIP enrichment obtained by DNA microarray hybridization and QPCR analysis.

Additional file 4: Figure S2. Pie chart displaying the fractions of functional classes to which the genes, closest to or overlapping the identified Ss-LrpB binding regions, belong.

Additional file 5: Figure S3. Zoomed profiles of ChIP-enriched regions (partially) covering two open reading frames or more.

Additional file 6: Figure S4. In vitro binding analysis to fragments representing ChIP-enriched genomic regions.

Additional file 7: Table S2. (Putative) binding motifs in the sequences bound by Ss-LrpB in vivo and in vitro.

Additional file 8: Figure S5. PCR analysis of genomic DNA targeting the genomic region that flanks Ss-IrpB and contains an ISC1078 element between positions 1959047 and 1960125 in the published S. solfataricus P2 genome sequence.

Additional file 9: Figure S6. Schematic representation of the Ss-IrpB operator structure in the case of absence of ISC1078.

Additional file 10: Table S3. In silico predicted Ss-LrpB binding sites (using the binding energy weight matrix) in regions upstream of S. solfataricus P2 ORFs (200 bp upstream of ORF start) with a theoretical $K_{D}$ lower than $5 \mu \mathrm{M}$.

Additional file 11: Figure S7. In vitro binding in the control region of gpT-1 (Sso2342)/ mtaP (Sso2343).

Additional file 12: Figure S8. In vitro binding to the separate Ss-LrpB binding sites identified in the Sso0049 and gpT-1/mtaP control regions.

Additional file 13: Figure S9. Primer extension analysis for TSS determination.

\section{Competing interests}

The authors declare that they have no competing interests.

\section{Authors' contributions}

Designed and coordinated the study: GH-G, SM, DC, EP. Performed experimental work: TND, NS, DC, EP. Contributed to data analysis: TND, LVO, EP. Drafted the manuscript: TND, EP. All authors read and approved the final manuscript.

\section{Acknowledgements}

The authors are grateful to Phu Nguyen Le Minh for the gift of purified PepA protein. This work was supported by the Research Foundation Flanders (FWO-Vlaanderen) (a postdoctoral fellowship to EP and a pre-doctoral fellowship to LvO), the Flemish Institute of Biotechnology (Vlaams Instituut voor Biotechnologie (VIB)), the Research Council of the Vrije Universiteit Brussel, 
the Vlaamse Gemeenschapscommissie, the China Scolarship Council (CSC) and the European Union (EU) (project 241481 (AFFINOMICS) to SM).

\section{Author details}

'Research group of Cellular and Molecular Immunology, Vrije Universiteit Brussel, Pleinlaan 2, B-1050 Brussels, Belgium. ${ }^{2}$ Department of Structural Biology, VIB, Pleinlaan 2, B-1050 Brussels, Belgium. ${ }^{3}$ Research group of Microbiology, Vrije Universiteit Brussel, Pleinlaan 2, B-1050 Brussels, Belgium. ${ }^{4}$ IMEC, Kapeldreef 75, B-3001 Leuven, Belgium. ${ }^{5}$ Department of Microbiology and Immunology, State University of New York at Buffalo, 321 Cary Hall, 3435 Main Street, 14214Buffalo, NY, United States.

Received: 13 June 2013 Accepted: 15 November 2013 Published: 25 November 2013

\section{References}

1. Kyrpides NC, Ouzounis CA: Transcription in archaea. Proc Natl Acad SCi USA 1999, 96:8545-8550.

2. Pérez-Rueda E, Collado-Vides J, Segovia L: Phylogenetic distribution of DNA-binding transcription factors in bacteria and archaea. Comput Biol Chem 2004, 28:341-350.

3. Charoensawan V, Wilson D, Teichmann SA: Genomic repertoires of DNAbinding transcription factors across the tree of life. Nucleic Acids Res 2010, 38:7364-7377.

4. Perez-Rueda E, Janga SC: Identification and genomic analysis of transcription factors in archaeal genomes exemplifies their functional architecture and evolutionary origin. Mol Biol Evol 2010, 27:1449-1459.

5. Brinkman AB, Ettema TJG, de Vos WM, van der Oost J: The Lrp family of transcriptional regulators. Mol Microbiol 2003, 48:287-294.

6. Ouhammouch M, Dewhurst RE, Hausner W, Thomm M, Geiduschek EP: Activation of archaeal transcription by recruitment of the TATA-binding protein. Proc Natl Acad Sci USA 2003, 100:5097-5102.

7. Ouhammouch M, Langham GE, Hausner W, Simpson AJ, El-Sayed NMA, Geiduschek EP: Promoter architecture and response to a positive regulator of archaeal transcription. Mol Microbiol 2005, 56:625-637.

8. Kawashima T, Aramaki H, Oyamada T, Makino K, Yamada M, Okamura H, Yokoyama K, Ishijima SA, Suzuki M: Transcription regulation by feast/ famine regulatory proteins, FFRPs, in archaea and eubacteria. Biol Pharm Bull 2008, 31:173-186.

9. Peeters E, Albers SV, Vassart A, Driessen AJM, Charlier D: Ss-LrpB, a transcriptional regulator from Sulfolobus solfataricus, regulates a gene cluster with a pyruvate ferredoxin oxidoreductase-encoding operon and permease genes. Mol Microbiol 2009, 71:972-988.

10. Brinkman AB, Bell SD, Lebbink RJ, de Vos WM, van der Oost J: The Sulfolobus solfataricus Lrp-like protein LysM regulates lysine biosynthesis in response to lysine availability. J Biol Chem 2002, 277:29537-29549.

11. Okamura H, Yokoyama K, Koike H, Yamada M, Shimowasa A, Kabasawa M, Kawashima T, Suzuki M: A structural code for discriminating between transcription signals revealed by the feast/famine regulatory protein DM1 in complex with ligands. Structure 2007, 15:1325-1338.

12. Yokoyama K, Ishijima SA, Koike H, Kurihara C, Shimowasa A, Kabasawa M, Kawashima T, Suzuki M: Feast/famine regulation by transcription factor FL11 for the survival of the hyperthermophilic archaeon Pyrococcus OT3. Structure 2007, 15:1542-1554.

13. Kumarevel T, Nakano N, Ponnuraj K, Gopinath SCB, Sakamoto K, Shinkai A, Kumar PKR, Yokoyama S: Crystal structure of glutamine receptor protein from Sulfolobus tokodaii strain 7 in complex with its effector L-glutamine: implications of effector binding in molecular association and DNA binding. Nucleic Acids Res 2008, 36:4808-4820.

14. Miyazono Kl, Tsujimura M, Kawarabayasi Y, Tanokura M: Crystal structure of STS042, a stand-alone RAM module protein, from hyperthermophilic archaeon Sulfolobus tokodaii strain 7. Proteins 2008, 71:1557-1562.

15. Schwaiger R, Schwarz C, Furtwangler K, Tarasov V, Wende A, Oesterhelt D: Transcriptional control by two leucine-responsive regulatory proteins in Halobacterium salinarum R1. BMC Mol Biol 2010, 11:40.

16. Song N, Nguyen Duc T, van Oeffelen L, Muyldermans S, Peeters E, Charlier D: Expanded target and cofactor repertoire for the transcriptional activator LysM from Sulfolobus. Nucleic Acids Res 2013, 41:2932-2949.

17. Yokoyama K, Ishijima SA, Clowney L, Koike H, Aramaki H, Tanaka C, Makino K, Suzuki M: Feast/famine regulatory proteins (FFRPs): Escherichia coli Lrp,
AsnC and related archaeal transcription factors. FEMS Microbiol Rev 2006, 30:89-108.

18. Vassart A, van Wolferen M, Orell A, Hong Y, Peeters E, Albers SV, Charlier D: SaLrp from Sulfolobus acidocaldarius is a versatile, glutamine-responsive, and architectural transcriptional regulator. Microbiology Open 2013, 2:75-93.

19. Peeters $E$, Charlier D: The Lrp family of transcription regulators in archaea. Archaea 2010, 2010:750457.

20. Ettema TJG, Brinkman AB, Tani TH, Rafferty JB, van der Oost J: A novel ligand-binding domain involved in regulation of amino acid metabolism in prokaryotes. J Biol Chem 2002, 277:37464-37468.

21. Brinkman AB, Dahlke I, Tuininga JE, Lammers T, Dumay $V$, de Heus $E$, Lebbink JH, Thomm M, de Vos WM, van der Oost J: An Lrp-like transcriptional regulator from the archaeon Pyrococcus furiosus is negatively autoregulated. J Biol Chem 2000, 275:38160-38169.

22. Enoru-Eta J, Gigot D, Thia-Toong TL, Glansdorff N, Charlier D: Purification and characterization of Sa-Lrp, a DNA-binding protein from the extreme thermoacidophilic archaeon Sulfolobus acidocaldarius homologous to the bacterial global transcriptional regulator Lrp. J Bacterio/ 2000, 182:3661-3672.

23. Leonard PM, Smits SH, Sedelnikova SE, Brinkman AB, de Vos WM, van der Oost J, Rice DW, Rafferty JB: Crystal structure of the Lrp-like transcriptional regulator from the archaeon Pyrococcus furiosus. EMBO J 2001, 20:990-997.

24. Ouhammouch M, Geiduschek EP: A thermostable platform for transcriptional regulation: the DNA-binding properties of two Lrp homologs from the hyperthermophilic archaeon Methanococcus jannaschii. EMBO J 2001 20:146-156.

25. Enoru-Eta J, Gigot D, Glansdorff N, Charlier D: High resolution contact probing of the Lrp-like DNA-binding protein Ss-Lrp from the hyperthermoacidophilic crenarchaeote Sulfolobus solfataricus P2. Mol Microbiol 2002, 45:1541-1555.

26. Koike H, Ishijima SA, Clowney L, Suzuki M: The archaeal feast/famine regulatory protein: potential roles of its assembly forms for regulating transcription. Proc Natl Acad Sci USA 2004, 101:2840-2845.

27. Peeters E, Willaert R, Maes D, Charlier D: Ss-LrpB from Sulfolobus solfataricus condenses about 100 base pairs of its own operator DNA into globular nucleoprotein complexes. J Biol Chem 2006, 281:11721-11728.

28. Pritchett MA, Wilkinson SP, Geiduschek EP, Ouhammouch M: Hybrid Ptr2-like activators of archaeal transcription. Mol Microbiol 2009, 74:582-593.

29. Peeters E, Thia-Toong TL, Gigot D, Maes D, Charlier D: Ss-LrpB, a novel Lrp-like regulator of Sulfolobus solfataricus $\mathrm{P} 2$, binds cooperatively to three conserved targets in its own control region. Mol Microbio/ 2004, 54:321-336

30. Peeters E, Peixeiro N, Sezonov G: Cis-regulatory logic in archaeal transcription. Biochem Soc Trans 2013, 41:326-331.

31. Peeters $E$, van Oeffelen L, Nadal M, Forterre $P$, Charlier D: A thermodynamic model of the cooperative interaction between the archaeal transcription factor Ss-LrpB and its tripartite operator DNA. Gene 2013, 524:330-340.

32. Peeters E, Wartel C, Maes D, Charlier D: Analysis of the DNA-binding sequence specificity of the archaeal transcriptional regulator Ss-LrpB from Sulfolobus solfataricus by systematic mutagenesis and high resolution contact probing. Nucleic Acids Res 2007, 35:623-633.

33. Schelert J, Dixit V, Hoang V, Simbahan J, Drozda M, Blum P: Occurrence and characterization of mercury resistance in the hyperthermophilic archaeon Sulfolobus solfataricus by use of gene disruption. J Bacteriol 2004, 186:427-437.

34. Brock TD, Brock KM, Belly RT, Weiss RL: Sulfolobus: a new genus of sulfur-oxidizing bacteria living at low pH and high temperature. Arch Mikrobiol 1972, 84:54-68.

35. Nguyen Duc T, Peeters E, Muyldermans S, Charlier D, Hassanzadeh-Ghassabeh G: Nanobody(R)-based chromatin immunoprecipitation/micro-array analysis for genome-wide identification of transcription factor DNA binding sites. Nucleic Acids Res 2012, 41:e59.

36. Toedling J, Huber W: Analyzing ChIP-chip data using bioconductor. PLoS Comput Biol 2008, 4:e1000227.

37. Bailey TL, Boden M, Buske FA, Frith M, Grant CE, Clementi L, Ren J, Li WW, Noble WS: MEME SUITE: tools for motif discovery and searching. Nucleic Acids Res 2009, 37:W202-W208.

38. Vieira J, Messing J: The pUC plasmids, an M13mp7-derived system for insertion mutagenesis and sequencing with synthetic universal primers. Gene 1982, 19:259-268. 
39. Maxam AM, Gilbert W: Sequencing end-labeled DNA with base-specific chemical cleavages. Meth Enzymol 1980, 65:499-560.

40. Rozen S, Skaletsky H: Primer3 on the WWW for general users and for biologist programmers. Methods Mol Biol 2000, 132:365-386.

41. Livak KJ, Schmittgen TD: Analysis of relative gene expression data using real-time quantitative PCR and the 2(-Delta Delta C(T)) Method. Methods 2001, 25:402-408.

42. Wurtzel O, Sapra R, Chen F, Zhu Y, Simmons BA, Sorek R: A single-base resolution map of an archaeal transcriptome. Genome Res 2010, 20:133-141.

43. She Q, Singh RK, Confalonieri F, Zivanovic Y, Allard G, Awayez MJ, Chan-Weiher CC, Clausen IG, Curtis BA, De Moors A, et al: The complete genome of the crenarchaeon Sulfolobus solfataricus P2. Proc Natl Acad Sci USA 2001, 98:7835-7840

44. Lillestøl RK, Shah SA, Brügger K, Redder P, Phan H, Christiansen J, Garrett RA: CRISPR families of the crenarchaeal genus Sulfolobus: bidirectional transcription and dynamic properties. Mol Microbiol 2009, 72:259-272.

45. Driessen RPC, Dame RT: Structure and dynamics of the crenarchaeal nucleoid. Biochem Soc Trans 2013, 41:321-325.

46. Smollett KL, Smith KM, Kahramanoglou C, Arnvig KB, Buxton RS, Davis EO: Global analysis of the regulon of the transcriptional repressor LexA, a key component of SOS response in Mycobacterium tuberculosis. J Biol Chem 2012, 287:22004-22014.

47. Grainger DC, Aiba H, Hurd D, Browning DF, Busby SJW: Transcription factor distribution in Escherichia coli: studies with FNR protein. Nucleic Acids Res 2007, 35:269-278.

48. Shimada T, Ishihama A, Busby SJW, Grainger DC: The Escherichia coli RutR transcription factor binds at targets within genes as well as intergenic regions. Nucleic Acids Res 2008, 36:3950-3955.

49. Cho BK, Federowicz S, Park YS, Zengler K, Palsson BØ: Deciphering the transcriptional regulatory logic of amino acid metabolism. Nat Chem Biol 2011, 8:65-71.

50. Schmid AK, Reiss DJ, Pan M, Koide T, Baliga NS: A single transcription factor regulates evolutionarily diverse but functionally linked metabolic pathways in response to nutrient availability. Mol Syst Biol 2009, 5:282.

51. Galagan J, Lyubetskaya A, Gomes A: ChIP-Seq and the complexity of bacterial transcriptional regulation. Curr Top Microbiol Immunol 2013, 363:43-68.

52. Tanay A: Extensive low-affinity transcriptional interactions in the yeast genome. Genome Res 2006, 16:962-972.

53. Li XY, MacArthur S, Bourgon R, Nix D, Pollard DA, lyer VN, Hechmer A, Simirenko L, Stapleton M, Luengo Hendriks CL, et al: Transcription factors bind thousands of active and inactive regions in the Drosophila blastoderm. PLOS Biol 2008, 6:e27.

54. Macquarrie KL, Fong AP, Morse RH, Tapscott SJ: Genome-wide transcription factor binding: beyond direct target regulation. Trends Genet 2011, 27:141-148.

55. Manica A, Schleper C: CRISPR-mediated defense mechanisms in the hyperthermophilic archaeal genus Sulfolobus. RNA biology 2013, 10:671-678.

56. Chan PP, Holmes AD, Smith AM, Tran D, Lowe TM: The UCSC Archaeal Genome Browser: 2012 update. Nucleic Acids Res 2012, 40:D646-D652.

\section{doi:10.1186/1471-2164-14-828}

Cite this article as: Nguyen-Duc et al:: The genome-wide binding profile of the Sulfolobus solfataricus transcription factor Ss-LrpB shows binding events beyond direct transcription regulation. BMC Genomics 2013 14:828.

\section{Submit your next manuscript to BioMed Central and take full advantage of:}

- Convenient online submission

- Thorough peer review

- No space constraints or color figure charges

- Immediate publication on acceptance

- Inclusion in PubMed, CAS, Scopus and Google Scholar

- Research which is freely available for redistribution 